\title{
Combined use of flexible bronchoscopy and video laryngoscopy for endotracheal intubation in patients with King laryngeal tube in situ
}

\author{
Mohammad El-Orbany, MD (1) • Phillip Schmid III, MD
}

Received: 1 June 2016/Accepted: 4 July 2016/Published online: 14 July 2016

(C) Canadian Anesthesiologists' Society 2016

\section{To the Editor,}

Dodd et al. ${ }^{1}$ described a simple, safe technique for tracheal intubation (TI) with the King laryngeal tube (LT) in situ using a video laryngoscope (VL) and a bougie. We commend the authors for describing a technique that can significantly decrease the need for a surgical airway. The authors did not address, however, how should the airway could be established in case visualization could not be achieved with the VL after deflating the King LT cuff. Difficult or impossible visualization could be expected as it was the reason the King LT was used in the first place. Tongue and pharyngeal edema resulting from cuff inflation pressure had been reported to exaggerate visualization difficulty. ${ }^{2}$ Failure of visualization after cuff deflation should therefore be expected in a certain percentage of these patients.

Should inability to visualize the cords with VL or to pass the bougie constitute an indication for a surgical airway? We describe an alternative technique by which the exchange can be accomplished with the King LT in place while keeping the cuff inflated. Our technique allows continuous, uninterrupted ventilation throughout the exchange procedure. It can be used initially as an alternative to the technique described by Dodd et al. or as a rescue attempt when visualization is impossible with their technique and before proceeding with a surgical airway. We use a VL, but instead of the bougie we use a

This letter is accompanied by a reply. Please see Can J Anesth 2016; 63: this issue.

M. El-Orbany, MD $(\bowtie) \cdot$ P. Schmid III, MD

Department of Anesthesiology, Medical College of Wisconsin, Milwaukee, WI, USA

e-mail: elorbany@mcw.edu flexible fibreoptic bronchoscope (FOB) preloaded with an endotracheal tube (ETT). Although FOB had been used through the lumen of the King $\mathrm{LT}^{3}{ }^{3}$ we prefer the extraluminal approach to avoid any possible interruption of ventilation in the presence of an unstable airway. The VL blade is introduced until the pharyngeal cuff is well visualized. The FOB is then inserted between the VL blade and the shaft of the King LT. It is then advanced distally beyond the tip of the blade between the tongue and the anterior surface of the cuff without deflating the cuff or interrupting ventilation. When the cords are visualized, the tip of the FOB is further advanced until the carina is visualized. The King LT cuff is then deflated, the ETT is advanced over the FOB into the trachea, and the King LT is removed. If the glottis cannot be visualized using FOB or $\mathrm{VL}$, tracheostomy is indicated to establish a definitive airway. It is prudent to have an emergency cricothyrotomy kit and experienced personnel available throughout the exchange procedure until successful and correct placement of the ETT is verified.

Funding Resources None.

Conflicts of interest None declared.

Editorial responsibility This submission was handled by Dr. Hilary P. Grocott, Editor-in-Chief, Canadian Journal of Anesthesia.

\section{References}

1. Dodd KW, Klein LR, Kornas RL, Driver BE, Ho JD, Reardon RF. Definitive airway management in emergency department patients with a King laryngeal tube ${ }^{\mathrm{TM}}$ in place: a simple and safe approach. Can J Anesth 2016; 63: 638-9. 
2. Subramanian A, Garcia-Marcinkiewicz AG, Brown DR, Brown $M J$, Diedrich DA. Definitive airway management of patients presenting with a pre-hospital inserted King LT(S)-D ${ }^{\mathrm{TM}}$ laryngeal tube airway: a historical cohort study. Can J Anesth 2016; 63: 27582.
3. Genzwuerker HV, Vollmer T, Ellinger $K$. Fibreoptic tracheal intubation after placement of the laryngeal tube. $\mathrm{Br} \mathrm{J}$ Anaesth 2002; 89: 733-8. 